Research Article

\title{
A Study of Quality and Proficiency of the Service Providers in Delivering the Adolescent and Youth Friendly Services under the Rashtriya Kishor Swasthya Karyakram Programme in Madhya Pradesh
}

\author{
Surya Bali', Kriti Yadavi², Yash Alok ${ }^{3}$
}

${ }^{1}$ Additional Professor, ${ }^{2}$ Senior Resident, ${ }^{3}$ Junior Resident, Department of Community and Family Medicine, All India Institute of Medical Sciences, Bhopal, India.

DOI: https://doi.org/10.24321/2349.2880.202011

I $\mathbf{N} \quad \mathbf{F} \mathbf{O}$

Corresponding Author:

Surya Bali, Department of Community and Family Medicine, All India Institute of Medical Sciences, Bhopal, India.

E-mail Id:

surya.cfm@aiimsbhopal.edu.in

Orcid Id:

https://orcid.org/0000-0002-6694-0025

How to cite this article:

Bali S, Yadav K, Alok Y. A Study of Quality and Proficiency of the Service Providers in Delivering the Adolescent and Youth Friendly Services under the Rashtriya Kishor Swasthya Karyakram Programme in Madhya Pradesh. Ind J Youth Adol Health 2020; 7(3): 1-9.

Date of Submission: 2020-12-28

Date of Acceptance: 2021-01-18

\section{$\begin{array}{llllllll}\mathbf{A} & \mathbf{B} & \mathbf{S} & \mathbf{T} & \mathbf{R} & \mathbf{A} & \mathbf{C} & \mathbf{T}\end{array}$}

\begin{abstract}
Despite existing frameworks for the improvement of adolescent reproductive health, there is a lack in provision of the Adolescent Friendly Health Services (AFHS). The primary objective of this study was to assess the quality and proficiency of service providers to deliver Adolescent Friendly Health Services (AFHS) in central India. Data was gathered by visiting 30 secondary and tertiary level health facilities to assess their infrastructure and preparedness for providing AFHS using a pre-designed questionnaire based on WHO guidelines for assessing quality. Descriptive analysis was done using SPSS v21 and Microsoft Excel. Quality of AFHS services was found to be poor in non- RKSK facilities. However the knowledge level, training status and counseling skills of the service provider was found to be highly substandard in both RKSK and Non-RKSK facilities. The RKSK program has not been properly implemented and has failed to make an impact where it was required.
\end{abstract}

Keywords: AFHS, Proficiency, Quality, RKSK

\section{Introduction}

The adolescent age group in India makes up for one fifth of the national population. This is the age group carrying the potential to take a country to an altogether different level of heights in the social and economic sectors. Seeds properly planted and nourished in this soil will have a bright, positive and resourceful impact on the future of the health goals of India. ${ }^{1}$
But where there are hopes, there are problems as well. This age group in India suffers from a number of problems, especially reproductive and sexual health related problems, to name a few. These problems include a risk for early, unplanned pregnancies and increased vulnerability to sexually transmitted diseases, which include the dreaded HIV as well. ${ }^{2}$ At least $35 \%$ of the reported cases of AIDS in the country were in the age group of youth around $2005-06 .{ }^{3} \mathrm{~A}$ 
study conducted around the same year showed that the rate of stunting in Indian adolescents was high. ${ }^{4}$ Keeping in mind the problems such as these, and more, the Government of India through the Ministry of Health and Family Welfare tried to address them in 2005 by preparing and putting into action the Adolescent Reproductive and Sexual Health (Adolescent $\mathrm{RSH}$ ) policy and guidelines keeping in mind its relevance in the National Health Mission. ${ }^{2}$ But the programme was only successful to a limited degree. It constantly suffered from the problems of substandard supplies, equipment and incapable management frameworks. The decreased community awareness further added to the failure. ${ }^{2}$ To give examples of the increased demand for an intervention even after the ARSH programme launch, there were about 46,000 adolescent girls and 49,000 adolescent boys infected with HIV in India in 2009, ${ }^{5}$ the percentage of underweight adolescent girls in India in 2012 was $47 \%$ and about 15$19 \%$ of the adolescent girls in the country were pregnant. ${ }^{6}$

In the wake of the year 2014, the Rashtriya Kishor Swasthya Karyakram(National Adolescent Health Programme) was launched by the ministry which broadened the scope of adolescent health further than just RSH but it maintained AFHS in clinics as a key component of its catalogue of programme features. $^{2}$

The baselines of the programme revolve around active adolescent participation and captaincy, gender equity and rational and fruitful collaboration with other sectors and their components. The programme aims for empowering all Indian adolescents to bear fruit of their full potential by making knowledgeable and reasonable decisions linked to their health and well being and by gaining access to the provisions and counsel by which they need to do so. RKSK holistically tackles the health needs of adolescents, as well as it has also introduced community-based interventions for them with respect to their situations with the help of peer educators. ${ }^{1}$

As defined by WHO an Adolescent Friendly Health Service should be accessible, equitable, acceptable, appropriate, comprehensive, effective and efficient. ${ }^{7,8}$

Under RKSK, AFHC comprises of a plethora of clinical and advisory services on various adolescent health problems, including but not limited to Sexual and Reproductive Health (SRH), Nutrition, Substance and drug abuse, Injuries and Violence (accounting for Gender based violence), Non Communicable Diseases and Mental Health. These services are provided through trained service providers- which include the MO, ANM and Counselors at AFHCs located at all levels of healthcare. ${ }^{1}$

Despite existing programs and policies directed towards improvement of adolescent reproductive health, there is a lack of provision of Adolescent Friendly Health Services
(AFHS), as well as it suffering from a failure to expand. Furthermore, the interventions have mostly been unable to separate the specific but clearly different reproductive health needs of married and unmarried adolescents. The setting up and functioning of AFHS facilities in line with programme guidelines would definitely ascertain the provision of a comprehensive constellation of services to the defined adolescent population in a comfortable atmosphere which provides them an extent of personalized time and space to discuss their problems, secrecy, an understanding of their viewpoint of the problems and compassion. However, as with all programs and schemes, the operation of the units and the facilities providing these services requires to be monitored to focus upon and deal with shortcomings, if any and to further build upon the strong points and the experiences. There is, however, a dearth of research pertaining to this topic and to the best of our knowledge; no study to evaluate AFHCs has been carried out in this part of the country. The study was, therefore, carried out with the aim of assessing AFHS implementation in designated facilities in 10 districts of MP. ${ }^{9}$

\section{Objectives}

- To study the quality of youth friendly health services provided on these facilities.

- To study the proficiency of service providers at these facilities.

- To ascertain the determinants of quality of care.

- To find out the hindrances in providing appropriate and adequate healthcare services to youths at these facilities and to lead the way forward.

\section{Materials and Methodology}

Study Design: This study was a cross-sectional study.

Study Setting: The study was conducted in 10 districts of the state in Madhya Pradesh. One district was chosen from each of the 10 administrative divisions of the state to ensure proper geographic representation. The districts selected in consultation with the NHM officials. One district hospital and two CHCs had been selected randomly from each 10 selected districts. Thus we had 10 district hospitals and 20 CHCs to cover in the study. The Districts were Chhatarpur, Datia, Dewas,,Guna, Harda, Jhabua, Mandla, Raisen, Satna and Umaria.

Sample Size: The study covered 30 public health institutions from 10 districts. The team covered one district hospital and two $\mathrm{CHC}$ from each of the study district.

Sampling Method: The study was a mix of RKSK and nonRKSK districts so that both components could be assessed in same facilities visited by the team. In the study $2 \mathrm{CHCs}$ were selected from each Districts. If the district had more than $2 \mathrm{CHCs}$ then facilities were selected randomly. 10 districts from each administrative zone of Madhya Pradesh 
had been selected after consultation with NHM officials. $2 \mathrm{CHCs}$ and 1 district hospital from each district had been selected randomly to make total sample size of 30 health institution for evaluation.

Sampling Unit: Health institutions were the unit of quantitative study. For the purpose of qualitative study service providers like AWW, ASHA and Counselors were the unit of study.

Duration: The study duration was 4 months. There were 15 days of recruitment, training \& orientation and desk review about the project. Data collection period was two months and one month for the Report writing.

Data Collection Tool: Data was collected through the predesigned pretested structured questionnaire through mobile based online data collection tool called ODK (realtime data collection). Data had been collected by the trained team of 3 members.

Quantitative Data: Data for the quantitative component of the study had been collected through a standard questions for the type of services provided at the facility, availability, demographic profile of service providers, training details, knowledge of service providers towards AFHS etc.

Qualitative Data: In-depth interviews were conducted with counselors for the qualitative component. During interviews they were asked about their knowledge, their perception, and their suggestions to improve the AFHS.

Data Analysis: The data was analyzed using Excel and SPSS version 21.0 and applicable statistical parameters like rate, ratio, proportion and other appropriate statistics were used as per the requirement. The results so obtained were used to assess the success and failure of AFHS.

Ethical Clearance: The proposal was submitted to Institutional Ethics Committee. The committee approved the project and gave ethical clearance to complete the study.
Written consent had been taken from the stakeholders like AWW, ASHA and counselors.

\section{Result}

Figure 1, shows the various services provided at the RKSK vs Non-RKSK facilities. The services for nutritional counseling and consultation, sexual and reproductive health and mental health counseling were available in majority of the RKSK and Non-RKSK health facilities. However, the service of NCD counseling, substance abuse and addiction and injuries and gender-based violence was comparatively less in the Non-RKSK facilities.

Table 1, depicts the demographic profile of the service provider at Adolescent and Youth-friendly health Clinics. About half $(46.7 \%)$ of the service providers in the RKSK facilities were in the age group of 25-30 years whereas in the Non RKSK facilities most were more than 40 years in age. More of the service providers were males in both RKSK and Non-RKSK facilities ( $86.7 \%$ and $60 \%$ respectively). In majority $(86.7 \%)$ of the RKSK facilities service provider was a trained counsellor. However the doctor was not a service provider in any of these facilities. In Non-RKSK facilities the service provider was either a doctor or trained counsellor. More of the RKSK facilities (86.7\%) had a trained provider as compared to Non-RKSK facilities (33.3\%).

It was found that counselors were available in only 22 health facilities out of the sampled 30 facilities. Total trained service providers were 18 and out of this, majority 17(94.4\%) of the service providers had received training from Bhopal and $1(5.6 \%)$ from Indore. Less than half $(43.3 \%)$ of the service providers received a training in RKSK.

The quality of the counselors was further evaluated on various domains. More of the counselors in the RKSK facilities listened to the client carefully, followed principles of counseling and made the client comfortable as compared to Non-RKSK facilities.

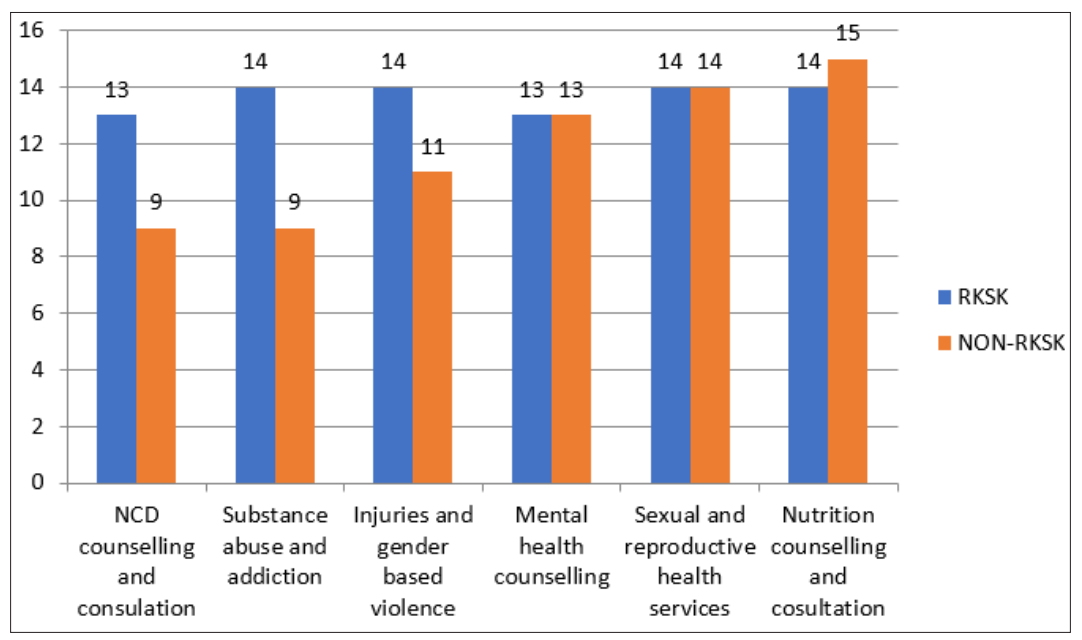

Figure I.Adolescent and Youth-friendly health services provided by RKSK vs Non-RKSK facilities $(\mathbf{N}=30)$ 
Table I.Demographic profile distribution of the service provider at RKSK vs Non-RKSK Adolescent and Youth-friendly health clinics $(\mathbf{N}=\mathbf{3 0})$

\begin{tabular}{|c|c|c|c|c|}
\hline Category & Sub Category & N (\%) & RKSK (\%) n=15 & Non RKSK (\%) n=15 \\
\hline \multirow{4}{*}{ Age } & 25 years - 30 years & $9(30)$ & $7(46.7)$ & $2(13.3)$ \\
\hline & 31 years - 35 years & $10(33.3)$ & $5(33.3)$ & $5(33.3)$ \\
\hline & 36 years - 40 years & $3(10)$ & $2(13.3)$ & $1(6.7)$ \\
\hline & $<40$ years & $8(26.7)$ & $1(6.7)$ & $7(46.7)$ \\
\hline \multirow{2}{*}{ Sex } & Male & $22(73.3)$ & $13(86.7)$ & $9(60)$ \\
\hline & Female & $8(26.7)$ & $2(13.3)$ & $6(40)$ \\
\hline \multirow{5}{*}{$\begin{array}{c}\text { Category/ } \\
\text { Designation }\end{array}$} & Doctor & $6(20)$ & 0 & $6(40)$ \\
\hline & Trained Nurse & $5(16.7)$ & $2(13.3)$ & $3(20)$ \\
\hline & Untrained Nurse & $1(3.3)$ & 0 & $1(6.7)$ \\
\hline & Trained Counselor & $17(56.7)$ & $12(80)$ & $5(33.3)$ \\
\hline & Untrained Counselor & $1(3.3)$ & $1(6.7)$ & 0 \\
\hline Formal Training & Yes & $18(60)$ & $13(86.7)$ & $5(33.3)$ \\
\hline \multirow{2}{*}{$\begin{array}{l}\text { Place of training } \\
\qquad(n=18)\end{array}$} & Bhopal & $17(56.7)$ & $13(86.7)$ & $4(26.7)$ \\
\hline & Indore & $1(3.3)$ & 0 & $1(6.7)$ \\
\hline \multirow{3}{*}{$\begin{array}{l}\text { Type of training } \\
\qquad(n=18)\end{array}$} & Family Planning & $1(3.3)$ & 0 & $1(6.7)$ \\
\hline & RTI/ STDs training & $4(13.3)$ & 0 & $4(26.7)$ \\
\hline & RKSK Training & $13(43.3)$ & $13(86.7)$ & 0 \\
\hline \multirow{3}{*}{$\begin{array}{l}\text { Total years of } \\
\text { experience }\end{array}$} & Less than one year & $4(13.3)$ & $4(26.7)$ & 0 \\
\hline & $2-5$ years & $11(36.7)$ & $7(46.7)$ & $4(26.7)$ \\
\hline & More than five years & $15(50)$ & $4(26.7)$ & $11(73.3)$ \\
\hline \multirow{3}{*}{$\begin{array}{l}\text { Quality of the } \\
\text { counsellor }(n=22)\end{array}$} & Counselor listen client carefully & $22(100)$ & $13(59.1)$ & 9 (40.9) \\
\hline & Counselor followed principles of counselling & $12(55.5)$ & $9(72.7)$ & $3(27.3)$ \\
\hline & Made Client comfortable & $12(55.5)$ & $5(41.7)$ & $7(58.3)$ \\
\hline
\end{tabular}

Figure 2, shows the distribution of quality of Adolescent and Youth-friendly health services provided by RKSK vs Non-RKSK facilities. In most of the RKSK facilities the quality of services was above satisfactory level as compared to Non-RKSK facilities where it was found to just satisfactory or poor.

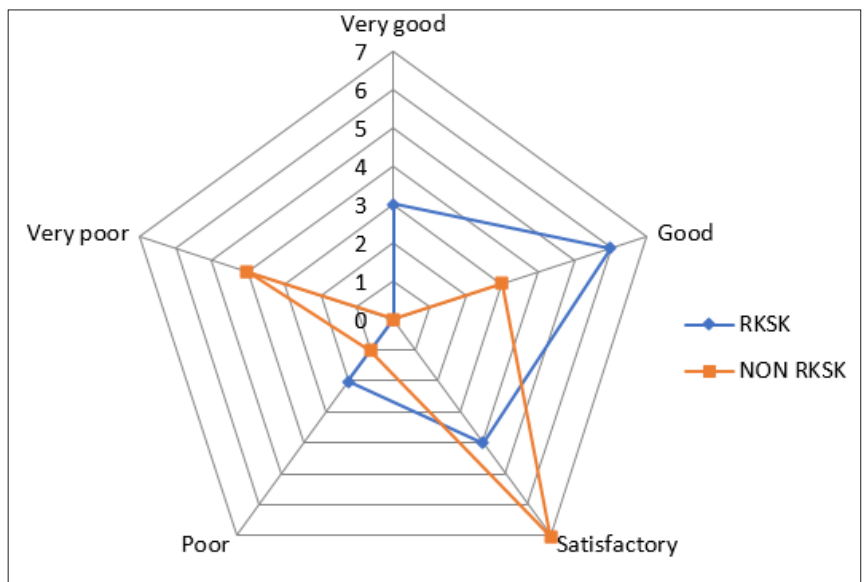

Figure 2.Quality of the Adolescent and Youth-friendly health services provided at the RKSK vs Non-RKSK health facilities $(\mathbf{N}=30)$ 
Table 2.Knowledge of provider towards adolescent and Youth-friendly health services in RKSK vs Non-RKSK facilities $(\mathbf{N}=\mathbf{3 0})$

\begin{tabular}{|c|c|c|c|c|c|}
\hline Category & Sub Category & N (\%) & $\begin{array}{c}\text { RKSK (\%) } \\
n=15\end{array}$ & $\begin{array}{l}\text { Non RKSK } \\
\text { (\%) } n=15\end{array}$ & p-value \\
\hline Correct age group of adolescent (10-19years) & Yes & $22(73.3)$ & $15(100)$ & $7(46.7)$ & $0.001 *$ \\
\hline Correct age group of Youth (15-24 years) & Yes & $2(6.7)$ & 0 & $2(13.3)$ & 0.483 \\
\hline Correct full form of RKSK & Yes & $21(70)$ & $14(93.3)$ & $7(46.7)$ & $0.014^{*}$ \\
\hline Correct full form of RBSK & Yes & $21(70)$ & $10(66.7)$ & $11(73.3)$ & 1.000 \\
\hline \multirow{3}{*}{$\begin{array}{c}\text { Knowledge of } 6 \text { Components of RKSK } \\
\text { Services }\end{array}$} & $\begin{array}{l}\text { Complete } \\
\text { Knowledge }\end{array}$ & $5(16.7)$ & $3(20)$ & $2(13.3)$ & 0.549 \\
\hline & Partial Knowledge & $24(80)$ & $12(80)$ & $12(80)$ & \\
\hline & No knowledge & $1(3.3)$ & 0 & $1(6.7)$ & \\
\hline \multirow{3}{*}{ Knowledge of Counseling Steps } & $\begin{array}{l}\text { Complete } \\
\text { Knowledge }\end{array}$ & $3(10)$ & 0 & $3(20)$ & 0.148 \\
\hline & Partial Knowledge & $11(36.7)$ & $7(46.7)$ & $4(26.7)$ & \\
\hline & No knowledge & $16(53.3)$ & $8(53.3)$ & $8(53.3)$ & \\
\hline $\begin{array}{l}\text { Knowledge of which contraceptive to be } \\
\text { advised to women with } 3 \text { children }\end{array}$ & Yes & 0 & 0 & 0 & 0 \\
\hline $\begin{array}{l}\text { Knowledge of which contraceptive to be } \\
\text { advised to women with one child }\end{array}$ & Yes & $21(70)$ & $9(60)$ & $12(80)$ & 0.328 \\
\hline $\begin{array}{l}\text { Knowledge of which contraceptive to be } \\
\text { advised to recently married women who has } \\
\text { no child }\end{array}$ & Yes & $9(30)$ & $5(33.3)$ & $4(26.7)$ & 0.539 \\
\hline $\begin{array}{l}\text { Knowledge that contraceptive is to be } \\
\text { provided to married women who are coming } \\
\text { alone to seek FP methods }\end{array}$ & Yes & $29(96.7)$ & $14(93.3)$ & $15(100)$ & 1.000 \\
\hline $\begin{array}{l}\text { Knowledge that contraceptive is to be } \\
\text { provided to unmarried women who come to } \\
\text { ask for contraceptive method }\end{array}$ & Yes & $17(56.7)$ & $6(40)$ & $11(73.3)$ & 0.139 \\
\hline $\begin{array}{l}\text { Knowledge that pregnancy test kit has to be } \\
\text { provided to a young girl who has missed her } \\
\text { periods }\end{array}$ & Yes & $6(20)$ & $5(33.3)$ & $1(6.7)$ & 0.169 \\
\hline $\begin{array}{l}\text { Knowledge that young/ adolescent in a } \\
\text { relationship has to be counseled about safe } \\
\text { sex and protection }\end{array}$ & Yes & $30(100)$ & $15(100)$ & $15(100)$ & - \\
\hline $\begin{array}{l}\text { Knowledge about providing abortion services } \\
\text { to married pregnant women with one child }\end{array}$ & Yes & $26(86.7)$ & $13(86.7)$ & $13(86.7)$ & 1.000 \\
\hline $\begin{array}{l}\text { Knowledge about whose consent is needed } \\
\text { before providing abortion services }\end{array}$ & Herself & $22(73.3)$ & $8(53.3)$ & $14(93.3)$ & $0.035^{*}$ \\
\hline \multirow[t]{2}{*}{ Overall Knowledge score } & Satisfactory & $2(6.7)$ & 0 & $2(13.3)$ & 0.483 \\
\hline & Unsatisfactory & $28(93.3)$ & $15(100)$ & $13(86.7)$ & \\
\hline
\end{tabular}

As per table 2, more of the service providers in RKSK facilities were aware about the correct age group of adolescents (10-19years) $100 \%$ and the correct full form of RKSK (Rashtriya Kishor Swasthya Karyakram) 93.3\% as compared to the Non-RKSK facilities $46.7 \%$ and this difference was found to be statistically significant. More of the service providers in RKSK facilities had complete knowledge of 6 Components of RKSK Services (Nutrition, Sexual reproductive health, Mental health, Injury and Violence, substance abuse and Non communicable diseases) 
whereas more of the service providers in Non-RKSK facilities had complete knowledge of couselling steps (GATHER= Greet, Ask, Tell, Help, Explain, and Return). However, the difference was not found to be statistically significant (Figure 3).

Most of the service providers in both RKSK and Non-RKSK facilities were not aware that which contraceptive has to be advised to women with 1 or 3 children. However, they suggested the correct contraceptive of choice in case of the recently married women with no children.
More of the service providers in Non-RKSK facilities had no knowledge that contraceptives are to be provided to unmarried women (73.3\%) as compared to RKSK facilities (40\%) but the difference was not found to be statistically significant.

Though all of the RKSK and Non-RKSK facilities had knowledge regarding counseling young/ adolescents in a relationship about safe sex and protection but only $20 \%$ of the service providers knew that a pregnancy test kit is to be provided to a young girl if she missed her period.
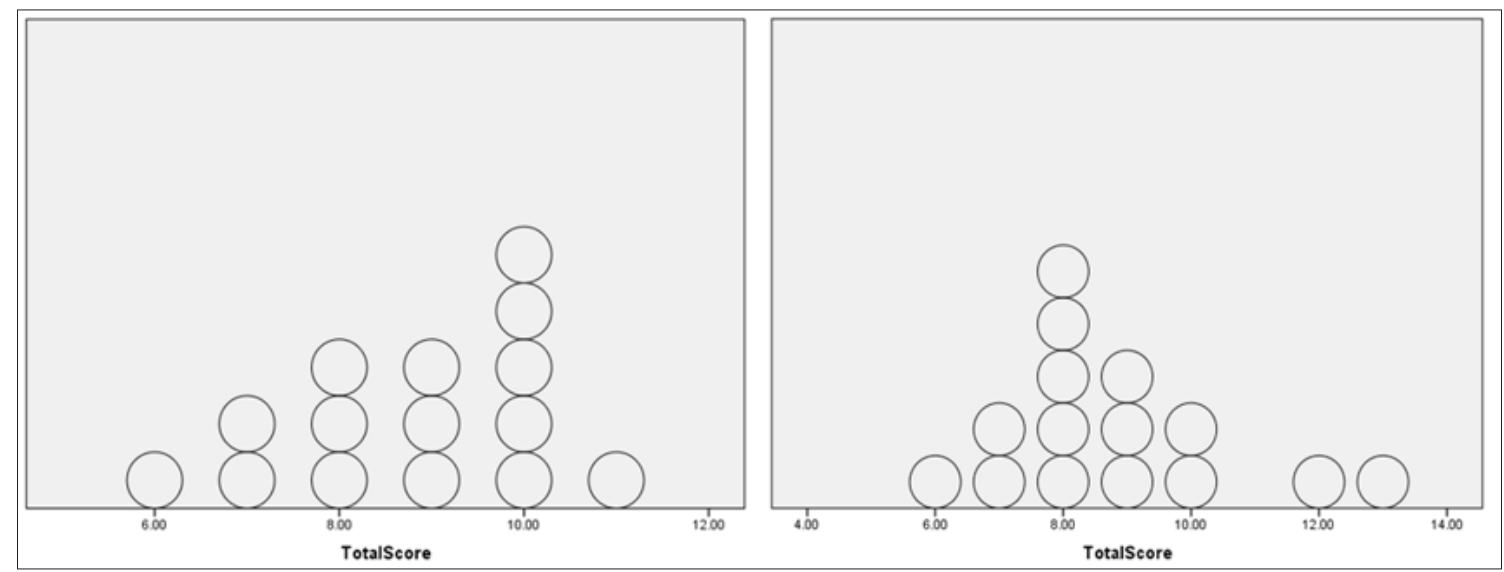

Figure 3.Mean (SD) RKSK-8.8 (I.424) vs Non-RKSK-8.8 (I.859) facility total knowledge score

Table 3.Determinants of quality of adolescent and Youth-friendly health services $(\mathbf{N}=30)$

\begin{tabular}{|c|c|c|c|c|c|c|}
\hline \multirow[b]{2}{*}{ Category } & \multirow[b]{2}{*}{ Sub category } & \multirow[b]{2}{*}{ N (\%) } & \multicolumn{3}{|c|}{ Service quality } & \multirow[b]{2}{*}{ p-value } \\
\hline & & & $\begin{array}{c}\text { Good }(\%) \\
n=12\end{array}$ & $\begin{array}{l}\text { Satisfactory } \\
\text { (\%) } n=11\end{array}$ & $\begin{array}{c}\text { Poor }(\%) \\
n=7\end{array}$ & \\
\hline \multirow{2}{*}{ Type of facility } & RKSK & $15(100)$ & $9(75)$ & $4(36.4)$ & $2(28.6)$ & 0.078 \\
\hline & Non-RKSK & $15(100)$ & $3(25)$ & $7(63.6)$ & $5(71.4)$ & \\
\hline \multirow{2}{*}{$\begin{array}{l}\text { Knowledge score of } \\
\text { the service provider }\end{array}$} & Satisfactory & $2(6.7)$ & 0 & 0 & $2(28.6)$ & $0.030 *$ \\
\hline & Unsatisfactory & $28(93.3)$ & $12(100)$ & $11(100)$ & $5(71.4)$ & \\
\hline \multirow{2}{*}{$\begin{array}{l}\text { Age of the service } \\
\text { provider }\end{array}$} & $\leq 35$ years & $19(63.3)$ & $11(91.7)$ & $8(72.7)$ & 0 & 0.000* \\
\hline & $>35$ years & $11(36.7)$ & $1(8.3)$ & $3(27.3)$ & 7 (100) & \\
\hline \multirow{2}{*}{$\begin{array}{c}\text { Sex of the service } \\
\text { provider }\end{array}$} & Male & $22(73.3)$ & $9(75)$ & $8(72.7)$ & $5(71.4)$ & 0.984 \\
\hline & Female & $8(26.7)$ & $3(25)$ & $3(27.3)$ & $2(28.6)$ & \\
\hline \multirow{2}{*}{$\begin{array}{l}\text { Designation of the } \\
\text { service provider }\end{array}$} & $\begin{array}{c}\text { Doctor, trained nurse/ } \\
\text { counsellor }\end{array}$ & $28(93.3)$ & $11(91.6)$ & $10(90.9)$ & $7(100)$ & $0.016^{*}$ \\
\hline & $\begin{array}{c}\text { Not trained nurse/ } \\
\text { counsellor }\end{array}$ & $2(6.7)$ & $1(8.4)$ & $1(9.1)$ & 0 & \\
\hline \multirow{2}{*}{$\begin{array}{c}\text { Training status of the } \\
\text { service provider }\end{array}$} & Trained & $18(60)$ & $10(83.3)$ & $6(54.5)$ & $2(28.6)$ & 0.057 \\
\hline & Untrained & $12(40)$ & $2(16.7)$ & $5(45.5)$ & $5(71.4)$ & \\
\hline \multirow{2}{*}{$\begin{array}{l}\text { Experience (years) of } \\
\text { the service provider }\end{array}$} & $<5$ years & $15(100)$ & $10(83.3)$ & $5(45.5)$ & 0 & $0.010^{*}$ \\
\hline & $>5$ years & $15(100)$ & $2(16.7)$ & $6(54.5)$ & $7(100)$ & \\
\hline \multirow{2}{*}{$\begin{array}{l}\text { Quality of counseling } \\
\qquad(n=22)\end{array}$} & Satisfactory & $12(54.6)$ & $10(83.3)$ & $2(18.2)$ & 0 & $0.02^{*}$ \\
\hline & Unsatisfactory & $10(45.4)$ & $2(16.7)$ & $5(45.5)$ & $3(42.9)$ & \\
\hline
\end{tabular}


An important finding was that the knowledge score of all the RKSK facility service providers was unsatisfactory.

More of the RKSK facilities (75\%) had good quality of services as compared to Non-RKSK facilities (25\%), however the differnce was found to be non-significant. The quality of service was found to be poor in facilities with providers having satisfactory knowledge score and the finding was statistically significant as well. The quality of service was also significantly associated with the designation of the service provider and was good if the provider was Doctor, trained nurse/ counsellor. The quality was good if the provider was trained but the association was statistically insignificant. The age and years of experience of the service provider were inversely associated with the quality of service; with quality being poor if the service provider was old and had $>5$ years of experience; association being statistically significant (Table 3).

Good quality of counselling i.e. listening to the client carefully, following principles of counseling and making client comfortable was also found to be significantly associated with good quality of AFHS.

\section{Discussion}

Provision of quality services at the health care facility should be provided to all adolescents irrespective of their economic status, age, gender, education, ethnicity, marital status, sexual orientation or any other characteristics, since it is a requirement for the adolescent health services to be equitable, comprehensive, and accessible as defined by the WHO. ${ }^{7}$ However in the current scene, the adolescent friendly health services provided are patchy, mismanaged, and of variable quality whether it is a RKSK facility or NonRKSK facility. ${ }^{10}$

In the present study though the quality of AFHS was found to be better in RKSK facilities as compared to Non-RKSK facilities, however no significant difference was observed between the two. This could have been due to the fact that even though the infrastructure for the programme is established in the RKSK facilities, the service providers take time in adapting to the new guidelines and may require repeated training sessions. Problems with the behaviour and attitude of the health care providers could be another reason. Whichever the case, the reason needs to be explored through further studies, possibly qualitative which focus upon the reasons for non improvement in the RKSK facilities. Similar findings have been reported by Kumar D et al., in their study in health facilities at Allahabad and Chandigarh, who found the quality of services a major matter requiring attention, which puts a big question mark on the execution of RKSK. ${ }^{11}$ Also, in a study done by Geary RS et.al. in South Africa no evidence was found suggesting the fact that the clinics that provided the YFS programme services transferred a more positive experience for the simulated clients, or their recommendation by the clients to their peers was more likely than those not providing these services. ${ }^{12}$

The competency and the skill of the are health care providers lie at the heart of quality service provision. For the young people to experience a positive attitude towards their issues, they are required to be properly guided by the service providers. Nevertheless, many of the healthcare service providers have reported substandard knowledge as well as technical skill, which is not an exclusive finding of only this study and has been reported by others as well. ${ }^{10}$ Knowledge score of all of the RKSK facility service providers was unsatisfactory and was similar for providers of both RKSK and Non-RKSK facilities which is worrisome for the programme as well as the target population. This could be due to the fact that the health care providers might have too much on their hands, or also the fact that they need a behavioral change intervention, or also lack of training/ monitoring which has gone on for quite a while now, or that the policy makers have a flaw in their understanding of the grass root level dynamics. The finding is similar to that reported by Dixit GT et al., in their study of UHCs in Ahemdabad. They reported that only about $20 \%$ of the trained healthcare service providers had the required technical competency. The overall score was found to be $47.3 \%$ which is near the benthos of the class interval $40 \%$ to $80 \%$ as per the WHO standard which is a red flag for interventions that bring about improvement. ${ }^{10}$ The findings reflect the failure of a national level adolescent health programme, which sadly, has very little backup as well. It is necessary as well as urgent that the stakeholders and health policy makers realize this fact and direct measures towards improving the executional status of the program. Researchers in their studies in Nepal also reported that providers suffered from lack of knowledge and poor understanding of the AFHS concept. ${ }^{12,13}$ Contrary to the findings of the present study an adequate knowledge was reported regarding all issues related with adolescents like ARSH, Mental Health, and Substance Abuse etc in a study done by Kumar $\mathrm{D}$ et al. ${ }^{11}$

In this study, the age of the service provider and years of experience were also found to influence the quality of AFHS with facility having a younger or less experienced provider having good quality services. This could be due to the fact that older individuals might have notions prevalent from a time when adolescent reproductive and sexual health was not stressed but rather frowned upon and a social taboo, as well as from the stigmas of the traditional Indian society ${ }^{14}$ and find it difficult to cope up with the changing trends in societal thinking. Also it could be due to the fact that they have problems grasping new concepts and require refresher trainings. Similar findings have been reported in Nepal 
where adolescents' experiences seemed to suggest that younger health care providers were more understanding and perhaps less judgmental of their problems. ${ }^{13}$ Gender of the provider, though found insignificant in our study was also an important determinant of the quality of services as the adolescents commonly experienced apprehension about the gender of the healthcare provider, thus affecting the service delivery. ${ }^{13}$ Such cases warrant behavioral change intervention sessions for the adolescents as well as educational sessions for the community so that more adolescents could readily ask for advice regarding their problems without hesitation regardless of the gender of the care provider. This also builds the trust of the people in the healthcare system.

Provision of age-appropriate information plus services to an adolescent client is considered one of the central and limiting aspects of AFHS. The service providers should have proper understanding of age-appropriate services, such as when to give information about menstruation, puberty, safe sex, or family planning. ${ }^{15}$ In this study providers were supportive of adolescents' right to comprehensive counseling and services. However some knowledge gap persisted, particularly concerning the provision of abortion services, contraception and condoms to unmarried adolescents and discomfort addressing the needs of those who are same-sex attracted. Unmarried adolescents were recognized as being particularly underserved because of community-level barriers and lack of knowledge and judgmental or discriminatory attitudes of providers. ${ }^{12,13}$ And it is not just the policy makers who are to blame. An equal responsibility lies on the shoulders of the building blocks of society such as teacher, village elders and parents. The adolescent health is not likely to improve if the traditional Indian society does not change its dogmatic ways and adopts a thinking that recognizes these problems for what they are. ${ }^{14}$

There were significantly more trained counselors in the facilities with RKSK implementation than without RKSK, but still the lacunae was found to be in both districts, which should have been absent at least in the districts where RKSK has been implemented. This shows the lethargic implementation of the programme. In the absence of counselor any duty doctor or nurse in charge was providing counseling services during the OPD time. Therefore counseling was not specific for A\& YFHS Services and all types of counselling, eg: Family planning, ICTC, STI/ RTI/ NRC, etc. was being provided.

Inadequate training, inadequate guidance skills and allocation of non ASRH-trained health care providers, degrades the quality of health care provided to adolescents. Due to this issue, it is important that frequent training is provided to all health care providers in ASRH across the country to maintain the quality of ASRH services in health facilities. ${ }^{12,13}$ The findings are comparable to that reported by Yadav et al in their study in three medical colleges at
Delhi, Kolkata and Chandigarh. Again the findings highlight the fact that the impact of the RKSK programme has not been successful. ${ }^{16}$ Significant areas where additional training was needed were communication, counseling and ARSH as reported by another study. ${ }^{11}$

Understandably, the trained providers who knew about GATHER approach listened attentively to the client as compared to where the services were delivered by clinical providers, which makes a case for improving and expanding the scope of training and placement of trained providers in all health care facilities. Similar findings have been reported by Wadhwa $\mathrm{R}$ et al. ${ }^{17}$ and Bhat et al. ${ }^{9}$ Contrary to the findings of the present study Dixit GT et al., reported that more than $70 \%$ provided health education, counseling and information about services and they provided services without discrimination, ${ }^{10}$ which provides a silver lining.

The majority of the providers reported that they felt confident to provide SRH services to adolescents, largely attributable to the training they had received prior to the inception of AFHS. It was seen that specific guidance concerning the provision of services to specific adolescent populations and other marginalized groups fell short with respect to AFHS policy and National ASRH Program Implementation Guidelines. Though most providers self-reported improved counseling and communication skills, it is blatantly evident that a lot of training is required to adopt and improve these skills. Most importantly, training to address judgmental attitudes and stigma, as well as education of the masses regarding the same is needed to improve quality of care and adolescents' confidence and trust in AFHS. ${ }^{12}$ Thus reinforcement and proper implementation of the program is the need of the hour with special focus on training of the health care providers along with education of the adolescents and their communities.

This study has its strengths in the facts that it is one of the few studies to evaluate the impact of RKSK in the state, since it is a relatively recent programme. Also, as the study was done in 30 randomly selected AFHS clinics in CHCs and District Hospitals of Madhya Pradesh the quantitative findings of the study could be considered generalizable to some extent. However, to correctly determine the implementation status and impact of RKSK, there is definitely a need for well-planned, large-scale studies using standardized methodologies to evaluate quality of AFHS clinics in India since the dynamics between the adolescent population and the healthcare system of the different states are quite variable in India. Moreover, the study suffers from the inherent limitations of a cross sectional study. The qualitative component might also be not generalizable.

\section{Conclusion and Recommendation}

The quality of AFHS services is found to be poor in non- RKSK 
facilities. However, the knowledge level, training status and counseling skills of the service provider was found to be highly unsatisfactory in both RKSK and Non-RKSK facilities. This indicates that the RKSK program has not been properly implemented and has failed to make an impact on adolescent health. A holistic approach incorporating a package of reorientation of the service providers, various stakeholders by improving their knowledge and upgrading their communication and counseling skills through repeated trainings and an altogether effective reimplementation of the program is desirable. Prime focus should be on capacity building of the health care providers to provide quality services and at the same time, it is essential to involve whole communities and policymakers in raising awareness towards this pertinent issue of adolescent health. Efforts to eliminate the identified barriers of judgmental attitudes and social stigmas should be made via education of the community.

\section{Funding}

Funding for this project was done by the UNICEF office for Madhya Pradesh, India with grant number(BFO/ $\mathrm{RCH} / 901 / 2017 / 164)$.

\section{Conflict of Interest: None}

\section{References}

1. Adolescent Friendly Health Clinics (AFHCs): National Health Mission. Accessed June 26, 2020. https://nhm.gov.in/index1.php?lang=1\&level=3\& sublinkid $=1247 \&$ lid $=421$

2. Hoopes AJ, Agarwal P, Bull S, Chandra-Mouli V. Measuring adolescent friendly health services in India: A scoping review of evaluations. Reprod Health 2016; 13. DOI:10.1186/s12978-016-0251-8.

3. Young People and HIV AIDS, Fact Sheet, India. World Health Organization. Accessed June 26, 2020. From: https://apps.who.int/iris/bitstream/ handle/10665/206181/B0368. pdf;jsessionid=D651 DCFB8C1EE121AEE5EE000D81E7B0?sequence $=1$

4. Haboubi GJ, Shaikh RB. A Comparison of the Nutritional Status of Adolescents from Selected Schools of South India and UAE: A Cross-sectional Study. Indian J Community Med Off Publ Indian Assoc Prev Soc Med 2009; 34(2): 108-111. DOI:10.4103/0970-0218.51230

5. Mehra B, Bhalla P, Rawat D. Indian adolescents and human immunodeficiency virus: A pilot study from Delhi. J Fam Med Prim Care 2016; 5(1): 187-189. DOI:10.4103/2249-4863.184665.

6. United Nations Children's Fund (UNICEF), United Nations Children's Fund (UNICEF). Progress for Children: A Report Card on Adolescents. Number 10; 2012.

7. Chatterjee S, Baltag V. World Health Organization, Department of Maternal N Child and Adolescent
Health, World Health Organization, Joint United Nations Programme on HIV/AIDS. Global Standards for Quality Health-Care Services for Adolescents: A Guide to Implement a Standards-Driven Approach to Improve the Quality of Health-Care Services for Adolescents. 2015. Accessed June 26, 2020. From: http://apps.who. int/iris/bitstream/10665/183935/1/9789241549332_ vol1_eng.pdf

8. Nath A, Garg S. Adolescent friendly health services in India: A need of the hour. Indian J Med Sci 2008; 62(11): 465-472. DOI:10.4103/0019-5359.48461

9. Bhat $A A$, Jan $Y$, Jan $R$, Mushtaq $B$, Yousuf S. Adolescent Friendly Health Centres: A Review from North India. 5.

10. 10. Dixit GT, Jain S, Mansuri F, Jakasania A. Adolescent friendly health services: where are we actually standing? Int J Community Med Public Health. 2017;4(3):820-824. doi:10.18203/2394-6040.ijcmph20170765

11. Kumar D, Yadav RJ, Pandey A. Health Care Providers' Perspectives Regarding Adolescent Friendly Health Services (AFHS). Int J Health Sci 2015; (8): 11.

12. Geary RS, Webb EL, Clarke L, Norris SA. Evaluating youthfriendly health services: young people's perspectives from a simulated client study in urban South Africa. Glob Health Action 2015; 8: 26080. DOI:10.3402/gha. v8.26080

13. Pandey PL, Seale H, Razee H. Exploring the factors impacting on access and acceptance of sexual and reproductive health services provided by adolescentfriendly health services in Nepal. PLOS ONE 2019; 14(8): e0220855. DOI:10.1371/journal.pone.0220855

14. Ismail S, Shajahan A, Sathyanarayana Rao TS, Wylie K. Adolescent sex education in India: Current perspectives. Indian J Psychiatry 2015; 57(4): 333-337. DOI:10.4103/0019-5545.171843

15. Ainul S, Ehsan I, Tanjeen T, Reichenbach L. Adolescent Friendly Health Corners (AFHCs) in selected government health facilities in Bangladesh: An early qualitative assessment. Reprod Health. Published online January 1, 2017. DOI:10.31899/rh7.1002.

16. Yadav RJ, Mehta R, Pandey A, Adhikari T. Evaluation of adolescent-Friendly Health Services in India. 2009; 32: 9.

17. Wadhwa R, Chaudhary N, Bisht $\mathrm{N}$ et al. Improving adolescent health services across high priority districts in 6 states of India: Learnings from an integrated reproductive maternal newborn child and adolescent health project. Indian J Community Med 2018; 43(5): 6. DOI:10.4103/ijcm.IJCM_38_18 